\title{
ДИНАМИЧЕСКИЕ ХАРАКТЕРИСТИКИ ДВИГАТЕЛЬНЫХ И КОГНИТИВНЫХ ФУНКЦИЙ У ЗАНИМАЮЩИХСЯ СПОРТИВНОЙ ГИМНАСТИКОЙ СТУДЕНТОВ
}

\author{
Будыка Е.В., Ениколопова Е.В., Володина Е.С., Комаров А.М. (МГУ имени \\ М.В. Ломоносова, Москва, Россия) \\ ev-mgu@yandex.ru; enikolopov@mail.ru; volodina.ka2015@yandex.ru; \\ drew1987@yandex.ru

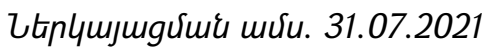 \\ 9pupunuर्ume uर्णu. 27.08.2021

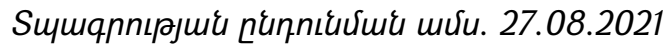

Настоящая работа посвящена анализу скоростных и регуляторных характеристик двигательных и когнитивных функций у занимающихся спортивной гимнастикой студентов разного пола и уровня спортивной квалификации. В исследовании принимали участие студенты различных факультетов МГУ имени М.В. Ломоносова-40 юношей и 26 девушек, у которых предварительно определялся профиль латеральной организации (ПЛО) моторных и сенсорных функций. Для изучения динамических составляющих двигательных функций применяли теппинг-тест и HandDominanz-Test (HDT). Оценку динамических характеристик когнитивных процессов проводили, используя словесно-цветовой интерференционный тест (Color-Word Interference Test)- модификацию теста Струпа из батареи D-KEFS и тест «Компас. Обнаружено, что скоростные характеристики и двигательных, и когнитивных функций были выше у юношей вне зависимости от уровня спортивной квалификации. Произвольная регуляция двигательных фрункций эффеективнее у девушек, чем у юношей. Результаты исследования свидетельствуют о том, что такой показатель произвольной регуляции познавательных процессов, как когнитивная гибкость, выше у юношей по сравнению с девушками и у более квалифрицированных спортсменов независимо от пола. Обсуждается связь индивидуальных особенностей моторных и познавательных процессов с успешностью в выбранном виде спорта.

Ключевые слова: студенты, спортивная гимнастика, двигательные и когнитивные прочессы.

DOI: https://doi.org/10.46991/SBMP/2021.4.2.114

Успешность в любом виде спорта зависит, в частности, от индивидуальных особенностей не только моторных, но и познавательных процессов $[1,4,5]$. Для выявления и описания индивидуальных характеристик эффрективно 
используется нейропсихологический подход к исследованию индивидуальных различий, уделяющий специальное внимание как мозговым механизмам этих различий, так и анализу разных компонентов психических процессов [3, 7]. Среди них важнейшими являются регуляторные (управляющие функции) $[8,10]$.

Актуальность настоящего исследования определяется недостаточностью сведений по проблеме индивидуальных различий скоростных и регуляторных показателей психической деятельности. Помимо теоретических, существуют и практические запросы для его проведения, в частности, с целью последующего учета полученных результатов для отбора и сопровождения индивидуальной подготовки спортсменов [4, 5].

Цель исследования: выявить у занимающихся спортивной гимнастикой студентов особенности динамических (скоростных и регуляторных) характеристик двигательных и когнитивных функций и фракторы, их определяющие.

В основу работы положена следующая гипотеза: существуют индивидуальные различия скоростных и регуляторных характеристик двигательных и когнитивных функций у занимающихся спортивной гимнастикой студентов, связанные с полом и уровнем спортивной квалификации.

Материалы и методы. В исследовании принимали участие 40 юношей и 26 девушек, студентов различных фракультетов МГУ имени М.В. Ломоносова, занимающихся спортивной гимнастикой. Средний возраст испытуемых-20,1 лет. Среди юношей спортивные разряды имеют 18 человек, без разряда-22. В группе девушек с разрядом 17 человек, без разряда - 9. Обследованная выборка характеризовалась выраженным преобладанием правосторонних признаков моторной и сенсорной асимметрии по сравнению с общей выборкой студентов МГУ [7], а также превалированием типов профиля латеральной организации (ПЛО) с выраженной праворукостью. Оценку латеральных признаков осуществляли в соответствии со схемой Е.Д. Хомской, И.В. Ефимовой [6]. Латеральные особенности, присущие гимнастам обследованной в настоящей работе выборки, соответствуют данным, представленным в литературе, о специфике латеральной организации моторной и сенсорных систем спортсменов со специализацией по спортивной гимнастике [1].

Для изучения динамических составляющих двигательных функций применяли теппинг-тест и Hand-Dominanz-Test (HDT) [2]. Оценку динамических характеристик когнитивных процессов проводили, используя словесноцветовой интерференционный тест (Color-Word Interference Test)- модификацию теста Струпа из батареи D-KEFS [9] и тест «Компас» [7].

При статистической обработке результатов пользовались пакетом прикладных программ SPSS Statistics 23.0. В качестве методов использовали: корреляционный анализ Пирсона, для сравнения двух групп между собой метод сравнения средних значений по t-критерию Стьюдента. Данные 
проверялись на нормальность распределения с помощью критерия ШапироУилка, проводилось сравнение дисперсий через критерий Ливиня. Значимыми признавались результаты, где p-value <0,05, результаты на уровне статистической тенденции - 0,05 $<$ p-value $<0,01$.

Результаты и их обсуждение. Проведенное исследование показало следующее. Были обнаружены значимые различия скоростных компонентов двигательных фрункций у испытуемых разного пола при использовании модели выполнения теппинг-теста каждой рукой и модели проведения сложной кривой (поочередно каждой рукой) в заданных границах (первый субтест методики HDT). Сравнительный анализ скоростных показателей выполнения теппингтеста для юношей и девушек осуществляли на основании суммарного числа ударов правой и левой рукой за ограниченный промежуток времени. Так, среднее суммарное количество ударов за 30 с для группы юношей составило

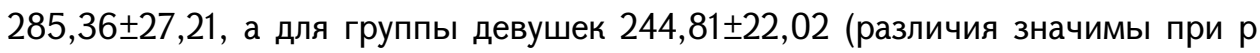
$<0,05)$. Это указывает на более высокие скоростные показатели движений рук у гимнастов мужского пола.

Задание первого субтеста методики HDT предполагает ограниченный временной промежуток (30 c) для проведения линии в «лабиринте», результаты его выполнения могут отражать скоростные возможности испытуемого. Значимо более высокая скорость обнаружена у обследованных юношей по сравнению с девушками при выполнении данного задания правой рукой (вне зависимости от уровня спортивной квалификации), что проиллюстрировано на рис. 1. Преимущество юношей по скорости выполнения задания прослеживалось и при выполнении теста левой рукой, но на уровне статистической тенденции (рис. 1).

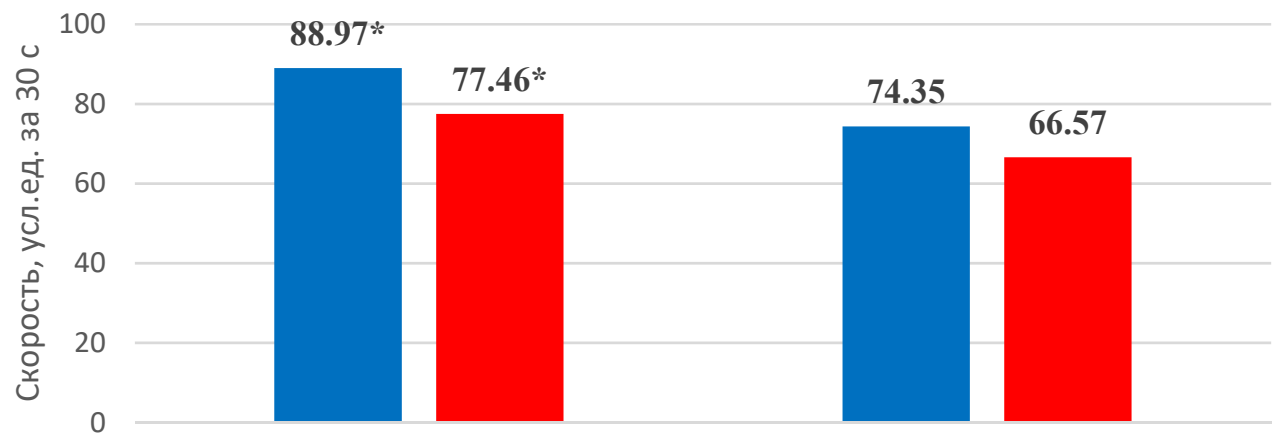

HDT Правая рука

HDT Левая рука

— Юноши в Девушки

Рисунок 1. Средние значения показателей выполнения субтеста «Проведение линии в лабиринте» теста НDT правой и левой рукой в группах юношей и девушек. 
Уровень значимости различий $p<0,05$. У испытуемых, различающихся уровнем спортивной квалификации, не выявлено значимых различий скоростных компонентов двигательных функций.

Полученные в настоящей работе результаты анализа скоростных характеристик когнитивных функций свидетельствуют о более высоких показателях осуществления серийных вербальных (в тесте Струпа) и зрительнопространственных операций (в тесте «Компас») юношами по сравнению с девушками. Так, например, среднее время выполнения задания второй серии

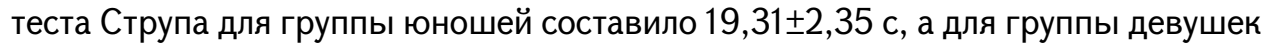
- 21,32 22,02 с. Различия значимы при $p<0,05$. При использовании другой модели изучения скоростных компонентов когнитивных функций - выполнения теста «Компас» - также были обнаружены различия у испытуемых разного пола. Полученные данные свидетельствуют о преимуществе юношей по сравнению с девушками по скорости выполнения теста «Компас», хотя оно не достигает уровня значимости, проявляясь на уровне тенденции. Различий скоростных показателей когнитивных функций в зависимости от уровня спортивной квалификации у испытуемых обследованной выборки не выявлено.

В качестве модели анализа произвольной регуляции движений использовали двукратное выполнение 2-го субтеста методики HDT («Проставление точек в кругах»). Испытуемому предлагалось поочередно правой и левой рукой сначала выполнить задание в оптимальном, удобном темпе, а затем в максимально быстром. Анализировались количество допущенных ошибок и продуктивность при различном темпе выполнения задания. На рис. 2 представлены средние значения числа ошибок, допущенных юношами и девушками при выполнении 2-го субтеста методики HDT правой и левой рукой в разном темпе.

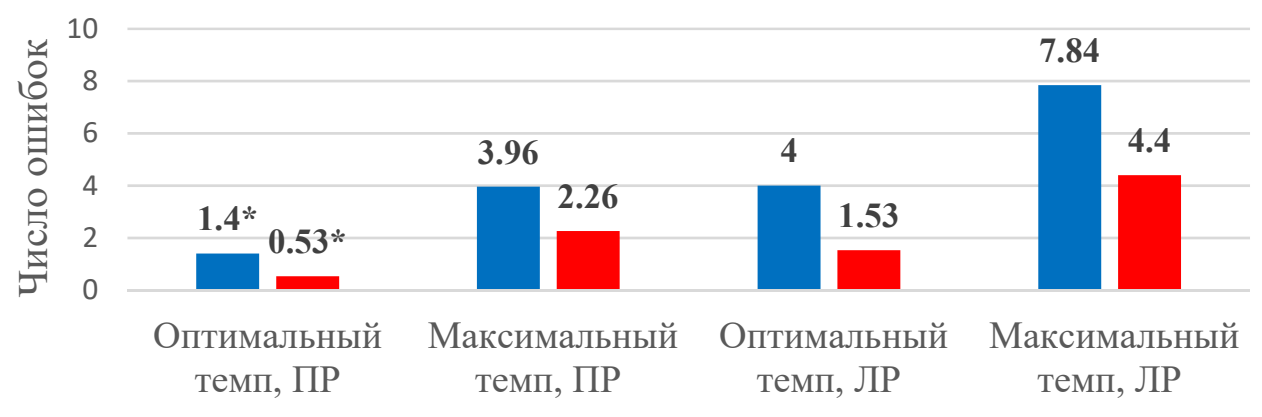

Серии исследования

- Юноши

- Девушки

Рисунок 2. Среднее количество ошибок для групп юношей и девушек при выполнении 2-го субтеста НDТ в разном темпе правой (ПР) и левой (ЛР) рукой. Уровень значимости различий $p<0,05$. 
Девушки допускали меньше ошибок, выполняя указанный субтест в разном темпе и правой, и левой рукой. Значимыми были различия юношей и девушек по количеству допущенных ошибок при выполнении 2-го субтеста HDT в оптимальном темпе правой рукой (рис. 2). У юношей ошибок больше, чем у девушек. При выполнении задания в оптимальном темпе левой рукой большее количество ошибок у юношей по сравнению с девушками прослеживалось на уровне статистической тенденции.

В соответствии с целью исследования были проанализированы регуляторные характеристики когнитивных функций в зависимости от пола и уровня спортивной квалификации. На модели теста Струпа для разных групп испытуемых проведен сравнительный анализ средних значений показателей «Тормозящий контроль», который не обнаружил значимых различий, и «Когнитивная гибкость». По последнему показателю были выявлены различия между юношами и девушками, а также гимнастами, имеющими и не имеющими спортивную квалификацию. Для анализа влияния последнего фрактора все студенты были распределены на 2 группы: первая группа - те, кто представляют сборную МГУ, но не имеют спортивного разряда, вторая студенты с различными уровнями спортивной квалифиикации. В соответствии с формулой расчета показателя «Когнитивная гибкость» лучшими являются меньшие значения. Усредненные для разных групп результаты демонстрируют, что лучшими показателями когнитивной гибкости характеризовались юноши

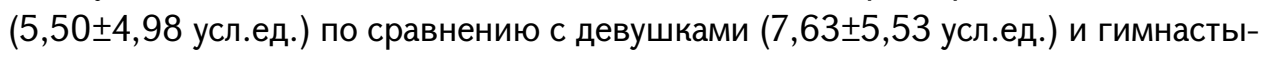
разрядники обоего пола. Последние осуществляют переключение с одной программы познавательной деятельности на другую эффрективнее $(6,53 \pm 5,19$

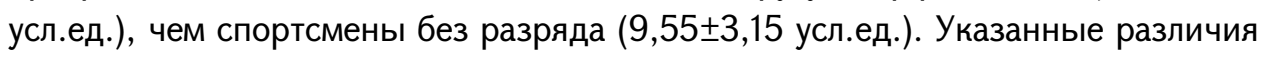
подтверждены на уровне статистической тенденции, тем не менее их можно интерпретировать как свидетельствующие о более высоких регуляторных возможностях в познавательной сфере у юношей, а также у квалифицированных гимнастов. В специальной литературе по индивидуализированному сопровождению подготовки спортсменов представлены мнения о роли не только двигательных, но и познавательных процессов в обеспечении успешных занятий тем или иным видом спорта [5], а также о положительном значении эфффективной произвольной регуляции различных фрункций [1]. Данные, полученные в настоящей работе, подтверждают указанные представления.

Полученные нами результаты могут являться предпосылкой для научного обоснования и разработки индивидуального подхода к обеспечению отбора, тренировочного и соревновательного этапов подготовки спортсменов, занимающихся гимнастикой. Перспективы исследования могут заключаться в изучении скоростных и регуляторных характеристик двигательных и когнитивных фрункций у гимнастов, а также у представителей других 
спортивных специализаций с учетом особенностей фрункциональной асимметрии.

Выводы

1. Подтверждена связь регуляторных и скоростных характеристик двигательных и когнитивных функций с полом и уровнем квалификации гимнастов.

2. Анализ связанных с полом различий по скоростным и регуляторным показателям выполнения разных видов деятельности выявил следующее:

- скоростные показатели двигательных и когнитивных функций выше у юношей по сравнению с девушками вне зависимости от уровня спортивной квалифиикации;

- произвольная регуляция двигательных фрункций эфффективнее у девушек, чем у юношей.

1. Получены данные, свидетельствующие о том, что когнитивная гибкость (как показатель произвольной регуляции познавательных процессов) выше на уровне статистической тенденции у юношей по сравнению с девушками и у более квалифицированных спортсменов обоего пола.

2. Полученные в работе результаты могут являться основанием для индивидуализированного обеспечения подготовки гимнастов.

\section{Литература}

1. Бердичевская Е.М., Гронская А.С. Функциональные асимметрии и спорт // Руководство по функциональной межполушарной асимметрии. - М.: Научный мир, 2009. - Глава 24. - с. 647-691.

2. Горина И.С., Степанова О.Б., Быкова А.В. Экспресс-методика, направленная на определение ведущей руки - «Hand-Dominanz-Test» (НDT) // Асимметрия. - 2013. - №1. - с.22-29.

3. Мачинская И.Р. Управляющие системы мозга // Журнал высшей нервной деятельности. - 2015. - Том. 65. - №1. - с. 33-60.

4. Психология спорта / под ред. Ю.П. Зинченко. - М.: Изд-во Московского университета, 2019. - 351 с.

5. Родионова И.А., Шалупин В.И. Развитие двигательных качеств студентов в процессе занятий фризической культурой с учетом принципа индивидуализации // Теория и практика физической культуры. - 2021. - №6. - с. 55-57.

6. Хомская Е.Д., Ефимова И.В. К проблеме типологии индивидуальных профилей межполушарной асимметрии мозга // Вестник Моск. ун-та. - 1991: серия 14 Психология. - №4. - с. 42-47. 
7. Хомская Е.Д., Ефимова И.В., Будыка Е.В., Ениколопова Е.В. Нейропсихология индивидуальных различий. - М.: Академия. - 2011. 160 c.

8. Diamond A. Executive functions //Annual review of psychology. - 2013. Vol. 64. - pp. 135-168.

9. Delis, D.C., Kaplan, E., Kramer, J.H. Delis-Kaplan Executive Function System. San Antonio: Psychological Corporation. - 2001. - 141 p.

10. Miyake A., Friedman N. P. The nature and organization of individual differences in executive functions four general conclusions //Current directions in psychological science. - 2012. - Vol. 21. - №. 1. - pp. 8-14.

\title{
DYNAMIC CHARACTERISTICS OF MOTOR AND COGNITIVE FUNCTIONS AMONG STUDENTS ENGAGED IN GYMNASTICS
}

\author{
Budyka E.V., Enikolopova E.V., Volodina E.S., Komarov A.M. (Moscow State \\ University, Moscow, Russia)
}

The present work is devoted to the analysis of the speed and regulatory characteristics of motor and cognitive functions in students of different genders and levels of sports qualification engaged in gymnastics. The study involved students of various faculties of the Lomonosov Moscow State University - 40 boys and 26 girls, whose lateral profile of motor and sensory functions was previously determined. Tapping test and Hand-Dominanz-Test (HDT) were used to study the dynamic components of motor functions. The dynamic characteristics of cognitive processes were evaluated using the Color-Word Interference Test - a modification of the Stroop test from the D-KEFS battery and the Compass test. It was found that the speed indicators of both motor and cognitive functions were higher in young men, regardless of the level of sports qualification. Voluntary regulation of motor functions is more effective among female students than among students. The results of the study indicate that such an indicator of the voluntary regulation of cognitive processes as cognitive flexibility is higher in young men compared to girls and in more highly qualified athletes, regardless of gender. The connection of individual characteristics of motor and cognitive processes with success in the chosen sport is discussed.

Keywords: students, gymnastics, executive functions, motor systems, cognitive processes. 